\title{
Numerical Simulation of Aerodynamics of Train with Broken Windows
}

\author{
J. Du, M. Yang, L. Zhang ${ }^{\dagger}$, F. Wu and W. Huang \\ Key Laboratory of Traffic Safety on Track of Ministry of Education, Central South University, Changsha, \\ Hunan 410075, China \\ Joint International Research Laboratory of Key Technology for Rail Traffic Safety, Changsha, Hunan \\ 410075, China \\ School of Traffic \& Transportation Engineering, Central South University, Changsha, Hunan 410075, China
}

†Corresponding Author Email: gszxzhanglei@126.com

(Received September 8, 2019; accepted February 3, 2020)

\begin{abstract}
Window glass of the train was broken several times when running in the strong wind/sandy areas, causing safety risks to passengers and serious problems to the operation of the train. The aerodynamic performances of the train with broken windows in strong wind condition are uncertain. These problems remain the challenging research issues. To study these issues, the influence of the broken windows on the aerodynamic performances of the train model was analyzed using three-dimensional numerical simulation methods. The results showed that the aerodynamic forces on the second passenger car first decreased and then increased within a very short period when the two middle windows on the windward side had been broken. However, the side force and the overturning moment increased sharply when the wind angle was increasing. In addition, the number of broken window glass has significant effects on train aerodynamics when running in cross wind area, and the absolute value of the side force and of the overturning moment increased significantly with the increase in the number of broken windows on windward side.
\end{abstract}

Keywords: Numerical simulation; Train window glass; Strong wind; Side force; Overturning moment.

\section{NOMENCLATURE}

$\begin{array}{ll}\mathrm{C}_{\mathrm{L}} & \text { lift force coefficients } \\ \mathrm{C}_{\mathrm{M}} & \text { overturning moment } \\ \mathrm{Cs}_{\mathrm{S}} & \text { side force coefficients } \\ H & \text { height of the train }\end{array}$

\section{INTRODUCTION}

The Lanzhou-Xinjiang railway line, which is one of the most important railway lines of China, is the artery that connects the economy, trade, and culture of Xinjiang with the inland cities. The train operating speed on this railway line has reached $250 \mathrm{~km} / \mathrm{h}$; however, the railway line crosses five strong-wind areas, including a well-known $100 \mathrm{~km}$ long strongwind area and a $30 \mathrm{~km}$ long strong-wind area. The wind in these areas is characterized by its long duration and short activation time; the highest wind speed reaches $64 \mathrm{~m} / \mathrm{s}$ and contains sand and gravel of various sizes ( $\mathrm{Li}$ et al. 2011; Li and Tian, 2012). The strong crosswinds have a severe effect on the aerodynamic forces and moments that act on the train (Baker and Reynolds, 1992; Hucho and 27 Sovran,

\author{
$L_{t} \quad$ length of the train \\ $V \quad$ wind speed \\ $W_{t} \quad$ width of the train \\ $Z \quad$ height referred to the ground
}

1993; Suzuki et al. 2003). Peters (2004) described that there has always been the occasional derailment due to strong side winds, but such accidents are more likely to happen not only in coastal areas but even in the very heart of larger continents. Strong side winds have induced several accidents, such as train overturning and track burying on this particular railway line, thus resulting in considerable damages. In addition, train windows have often been broken in these two strong-wind areas.

There were many studies have been focused on the safety problems of the train operation in the strong wind area, and fruitful outcomes have been achieved. Baker (1986) and Bocciolone et al. (2008) conducted moving-model experiments and wind-tunnel tests, respectively; they found that the stability, the 
possibility of the train overturning, and the vibration acceleration of the train increased with the increase in the running speed under strong-wind conditions. Bettle et al. (2003), Cheli et al. (2010), Hemida and Baker (2010), Sanquer et al. (2004), and Shirai and Ueda (2003) investigated the aerodynamic behavior of a train subjected to crosswind using computational fluid dynamics (CFD) simulation methods to assess the risk of the train overturning. Krajnović (2008) studied the influence of a wind gust on the flow around an ICE2 high-speed train when exiting a tunnel using the detached eddy simulation method, and found that the maximal yawing and rolling moments which possibly can cause a derailment or overturning were found to occur when approximately one third and one half of the train, respectively, has left the tunnel. García et al. (2017) studied the aerodynamic behavior of a full scale train under synthetic crosswind based on the Large Eddy Simulation (LES) method. Both smooth and rough train surfaces are considered in this study, and the force and moments acting on the train were obtained and analyzed. The experimental test was carried out to validate the numerical simulation results and facilitate the analysis. In addition, numerical results showed good agreements with the experimental results. Zhang et al. (2017) studied the effect of the wind break walls with different parameters on the aerodynamic performances of a high-speed train. Three-dimensional RANS turbulence model kepsilon was used to for the simulation, and a optimized shape of windbreak wall was proposed. Based on similar simulating method, Ji et al. (2019) proposed an optimization method used for design of the parameters of pantograph network monitoring device on high-speed train, and the aerodynamic performance of the proposed shape was better than others. Wang et al. (2014) carried out numerical and experimental studies to investigate the sensibility of aerodynamic characteristic to the rear shape, and provide more comprehensive experimental data as a reference to validate the numerical simulation. In this study, realizable k-epsilon model was employed to compute the aerodynamic drag, lift and surface pressure distribution, and the computational results showed a good agreement with the experimental data and the results from the wind tunnel tests. Based on all aforementioned studies, the railway department developed management methods for train operation in strong-wind areas. Paz et al. (2015) studied the influences of windblown sand on the aerodynamic performance of the train. The focal point of this study was the evaluation of the effect of windblown sand in desert areas on the drag resistance and the wear of the surface of a train. In addition, a train model was constructed as a compact body without windows; therefore, the influence of the windblown sand on the window glass was not considered.

However, railway maintenance still faces certain issues in terms of solving the problem of train window breakage (Ge and Jiang. 2009; Xu et al. 2014). In the studied area, the wind with a recorded maximum speed of $64 \mathrm{~m} / \mathrm{s}$ is very strong and its duration lasts considerably longer than in other areas in China, thus resulting in a great change in the pressure that is applied on the train window glass. The influence of the broken train windows on the aerodynamic performance of the train is uncertain. The wind may blow from the broken windows to the interior of the train within a short period, thus resulting in a sharp pressure change on the surface and the interior of the train. These pressure changes may severely affect the aerodynamic performance of the train and may compromise the safety of the passengers. Therefore, numerical simulations were conducted to analyze the effects of the broken windows on the aerodynamic performance of the train.

\section{The Aerodynamic EFfects of BROKEN WINDOWS}

When a train with broken windows encounters strong wind in an area with both strong wind and gravel, the air instantaneously flows into the coach body at a high speed, thus causing great changes in the pressure and the flow structure(Imai et al. 2002; Gao et al. 2014). The sudden change in the airflows will affect the aerodynamic performance of the train; thus, the evolution and the development of the flow field in the interior of the train should be simulated to assess the influence of the broken windows on the aerodynamic performance of the train.

\subsection{Calculation Model and Method}

In this study, a full-scale train model consisting of four cars (a locomotive and three passenger coaches) was adopted for the numerical simulation; the bogies, the fuel tanks, and the windshields were simplified. The entire length of the train model, $L_{t}$, was $101.3 \mathrm{~m}$ and the height of the passenger car, $H$, which was defined as the distance from the track surface to the top point of the car, was $4.433 \mathrm{~m}$. The width values $W_{t}$ of the locomotive and passenger coach are $3.3 \mathrm{~m}$ and $3.1 \mathrm{~m}$, respectively. According to the EN standards (CEN European Standard, 2008, 2009, 2010), it is best to set at least one car between two other cars when studying the aerodynamic performance of the train model under crosswinds conditions. Thus, in the present study, the investigation of the train aerodynamic performance was focused on the second passenger train. In addition, 12 windows were arranged on the second passenger car; the aerodynamic performance of the second passenger car was studied when the 6th and 7 th windows were broken. The train model with its dimensions is shown in Fig. 1 and the window details are shown in Fig. 2.

According to the studies of Zhang et al. (2016) and Niu et al. (2017a), appropriate turbulence model has to be adopted for different mesh discretization methods. Hence, in this study, the $R N G k-\varepsilon$ double equation turbulence model and the tetrahedral unstructured grids were adopted for solution of the flow field around the train model. In the simulation, the minimum size of the grid located on the train surface is $8 \mathrm{~mm}$. The tetrahedral unstructured grids were used for the discretization owing to the complex shape of the train, and the maximum 


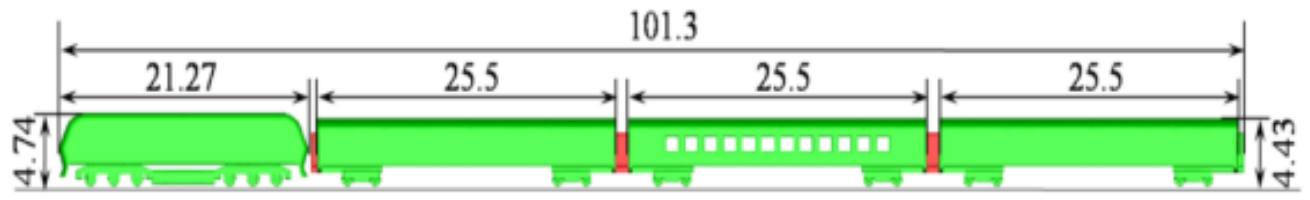

Fig. 1. The train model and its dimensions (m).

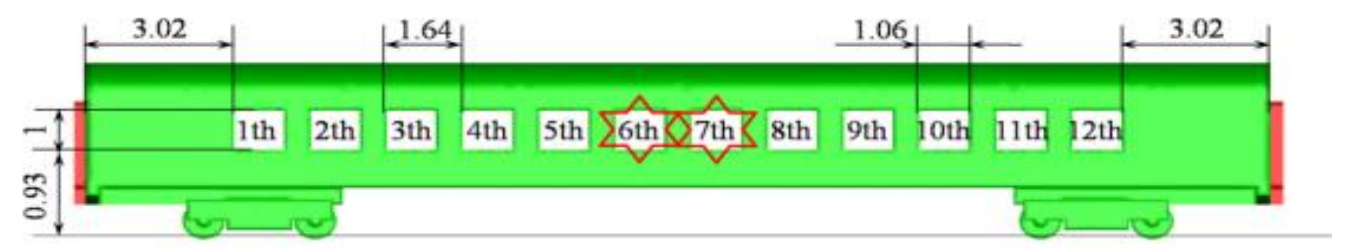

Fig. 2. Details of the windows on the second passenger car (m).

skewness ratio of the cells close to the train surface is 0.83 ( (Fluent Inc. 2006). The standard wall function (in Fluent software) was adopted for the train surface, and most of $y+$ in the simulation was in the range of 30-300. The second-order upwind scheme and the SIMPLEC (Semi-Implicit Method for Pressure-Linked Equations-Consistent) algorithm were chosen for the simulation using the commercial CFD software of Fluent. To control the convergence of the simulation, the continuity in the Fluent was set as $10^{-6}$.

Figure 3 shows the mesh on the second passenger car, the windows of which have all been broken because the aerodynamic performance of the second passenger car was also investigated when all windows had been broken. The grids around the train model are shown in Fig. 4.

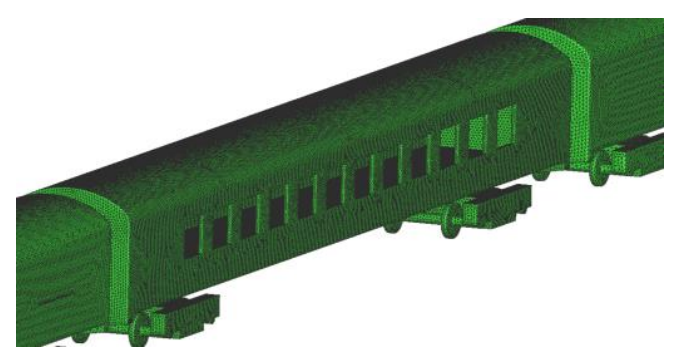

Fig. 3. Grids on the train model.

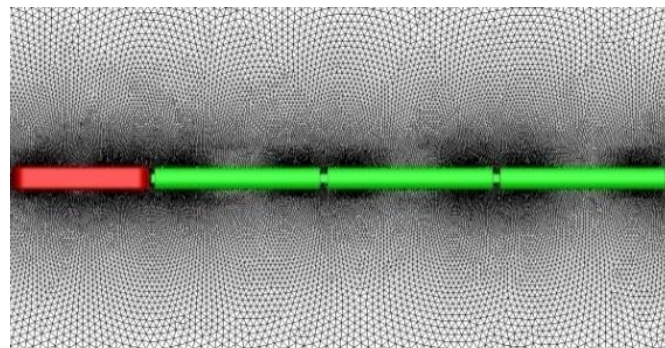

Fig. 4. The grids around the train model.

In addition, the boundary conditions and the dimensions of the computational domain are shown in Fig. 5. The velocity inlet boundary condition was adopted for the simulation of the incoming flow according to the studies of (Baker. 2010; Huang et al. 2016; Niu et al. 2017b; Xu et al. 2017). Therefore, the velocity inlet boundary condition in Fluent 14.0 was adopted for faces $\mathrm{ABCD}$ and $\mathrm{ABFE}$ of the computational domain. The composed velocity included the wind speed; the train speed was obtained through the velocity boundary condition on the computational domain. The definition of the compound velocity is shown in Fig. 6. In this study, the compound velocity, $U \mathrm{r}=30 \mathrm{~m} / \mathrm{s}$, was uniform (constant in time) and the yaw angle was $\beta$. To simulate the relative movement between the train model and the ground, the slip wall condition was adopted for the ground (face ADHE), where the slip velocity corresponded to the train speed. The top face, the back face, and the remaining side face of the computational domain constituted the pressure outlet boundary condition; the reference pressure, $\mathrm{P}$, was 0 Pa.

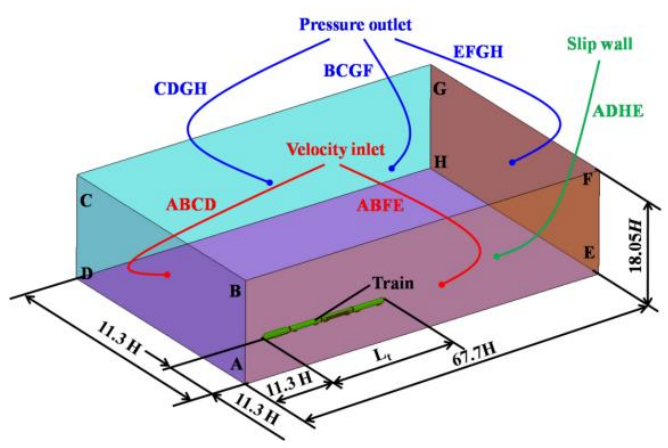

Fig. 5. Boundary conditions and dimensions of the computational domain.

\subsection{Validation of Numerical Simulation Method}

Before the final mesh resolution used in this simulation was decided, mesh sensitivity has to be studied. Additionally, the applicability of $R N G k-\varepsilon$ turbulence model for this study should be verified. Because of the complexity of the wind condition, it is very difficult to carry out a real test on 


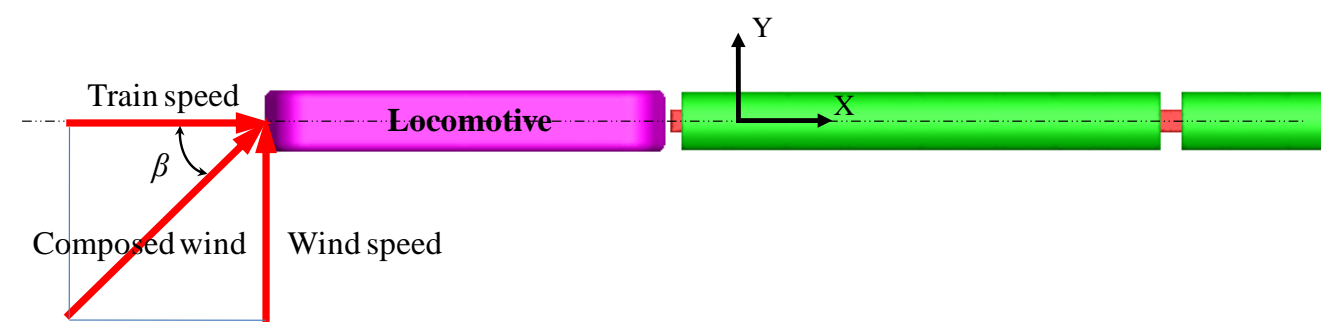

Fig. 6. Definition of the composed wind and yaw angle.

Table 1 Comparison of the side force for the whole train between numerical simulation results and the full-scale test

\begin{tabular}{|c|c|c|c|c|c|c|c|c|c|}
\hline \multirow{2}{*}{$\begin{array}{c}\text { Grid } \\
\text { number }\end{array}$} & \multicolumn{3}{|c|}{$\mathrm{C}_{\mathrm{s}}$} & \multicolumn{3}{|c|}{$\mathrm{C}_{\mathrm{L}}$} & \multicolumn{3}{|c|}{$\mathrm{C}_{\mathrm{M}}$} \\
\hline & Simulation & Test & Error & Simulation & Test & Error & $\begin{array}{c}\text { Simulatio } \\
n\end{array}$ & Test & Error \\
\hline 10000000 & 4.28 & \multirow{4}{*}{4.44} & $-3.60 \%$ & 6.92 & \multirow{4}{*}{7.48} & $-7.49 \%$ & 3.47 & \multirow{4}{*}{3.59} & $-3.34 \%$ \\
\hline 12000000 & 4.28 & & $-3.60 \%$ & 6.95 & & $-7.09 \%$ & 3.49 & & $-2.79 \%$ \\
\hline 14000000 & 4.31 & & $-2.93 \%$ & 6.98 & & $-6.68 \%$ & 3.51 & & $-2.23 \%$ \\
\hline 16000000 & 4.32 & & $-2.70 \%$ & 6.98 & & $-6.68 \%$ & 3.53 & & $-1.67 \%$ \\
\hline
\end{tabular}

aerodynamics of train with broken windows. However, the real test on aerodynamic of the train without broken windows used in this study had been carried out by Xiong et al. (2006). In order to validate the simulation method, including the boundary conditions of the computing domain, the applicability of $R N G k-\varepsilon$ turbulence model and the mesh adopted by this study, the numerical results of the side force coefficients $\left(C_{S}\right)$, lift force coefficients $\left(C_{L}\right)$ and the overturning moment $\left(C_{M}\right)$ were compared with the full-scale test data provided by Xiong et al. (2006) and Zhang et al. (2017), as shown in Table 1.

According to the CEN European Standard (CEN European Standard, 2008, 2009, 2010), the aerodynamic coefficients $C_{P}, C_{S}, C_{L}$ and $C_{M}$ are defined as follows:

Pressure coefficient: $C_{P}=\frac{P}{0.5 \rho U_{r e f}^{2}}$

Side force coefficient: $C_{S}=\frac{F_{S}}{0.5 \rho U_{r e f}^{2} S}$

Lift force coefficient: $C_{L}=\frac{F_{L}}{0.5 \rho U_{r e f}{ }^{2} S}$

Overturning moment coefficient:

$C_{M}=\frac{M}{0.5 \rho U_{r e f}^{2} S H}$

where $U_{\text {ref }}$ denotes the train speed, $U_{\text {ref }}=230 \mathrm{~km} / \mathrm{h}$, the flow density $\rho$ is $1.225 \mathrm{~kg} / \mathrm{m}^{3}$, and $S$ is the reference area of the train model, $H$ is the reference height, defined as the distance from the track surface to the top point of the car. In this study, $S=10 \mathrm{~m}^{2}$, $H=4.43 \mathrm{~m}$, and $F_{S}, F_{L}$, and $M$, are the side force, lift force and overturning moment, respectively, $P$ is the pressure change of monitoring point located on train surface.

The comparison in Table 1 presents that when using the $R N G k-\varepsilon$ turbulence model and 14000000 grids for the discretization, the numerical results show good agreement with the experimental data.

\subsection{The Effect of the Broken Windows on the Flow and the Aerodynamic Forces}

The sudden breakage of the train window glass inevitably causes severe flow structure changes in the interior of the train. Based on the numerical simulation results, the pressure changes and the development of the slipstream over time were analyzed. In the simulation configuration, the 6th and 7 th windows at the windward side, were assumed to be broken. The wind direction in this study is $45^{\circ}$, thereby, the wind can be decomposed according to the wind angle shown in Fig. 6. Thus, one of the decomposed winds was opposite to the running direction of the train, while the other one was perpendicular to the running direction of the train moved, and the train speed along the $\mathrm{X}$-direction and the crosswind speeds along the Y-direction were both $21.21 \mathrm{~m} / \mathrm{s}$. In the simulation, the train model without broken windows and train with broken windows were simulated separately, but the settings of the simulations were the same. Thus, these simulation configurations can be compared with each other. To facilitate the analysis, the window glass was assumed break at the time of $1 \mathrm{~s}$, which was just an assumed time for the comparison of different configurations. Figures 7 and 8 show the streamline and the pressure distribution of the crosssection located on the center of the 6th window.

Figure 7(a) indicates that prior to the glass breakage, the upwind flow of the coach had been divided into two parts at the bottom of the window. One part flows upward across the roof of the train, whereas the other part flows toward the bottom of the train body; no flows penetrated the body. On the leeward side of 

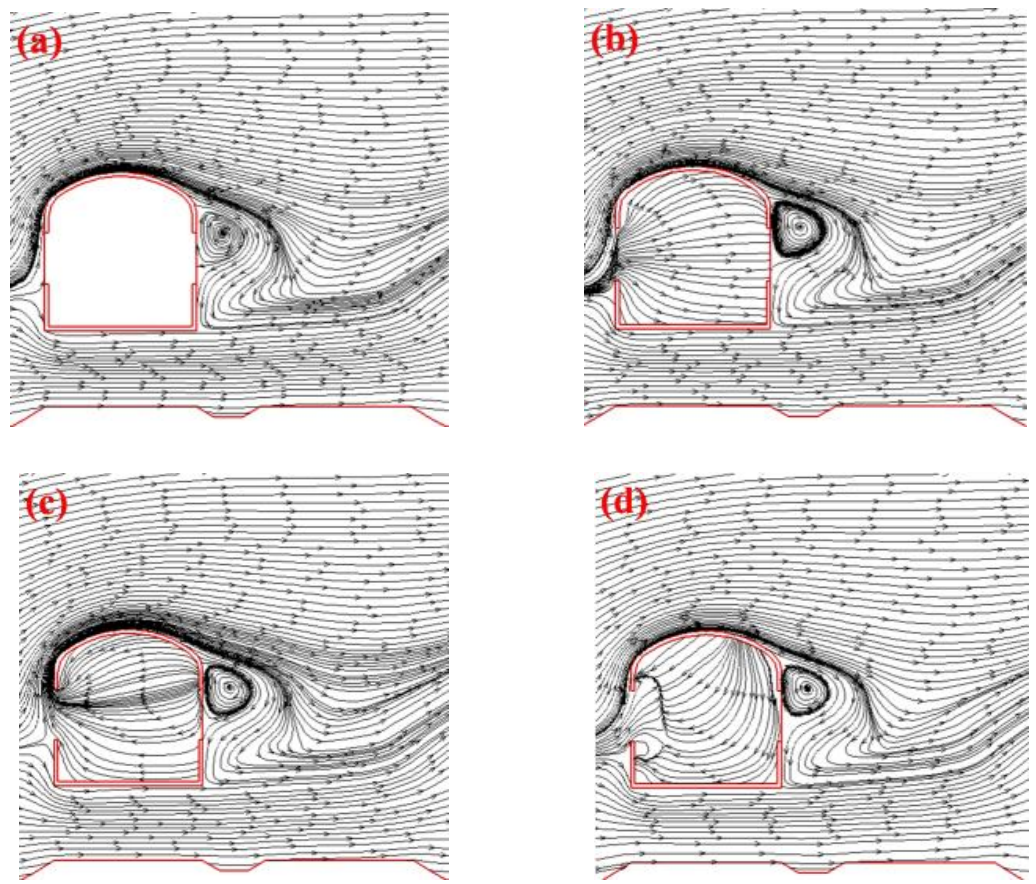

Fig. 7. Air streamlines at the coach cross-sectional surface: (a) $t=0.5 s$, (b) $t=1.01 s$, (c) $t=1.08 s$, (d) $t=4$ s.
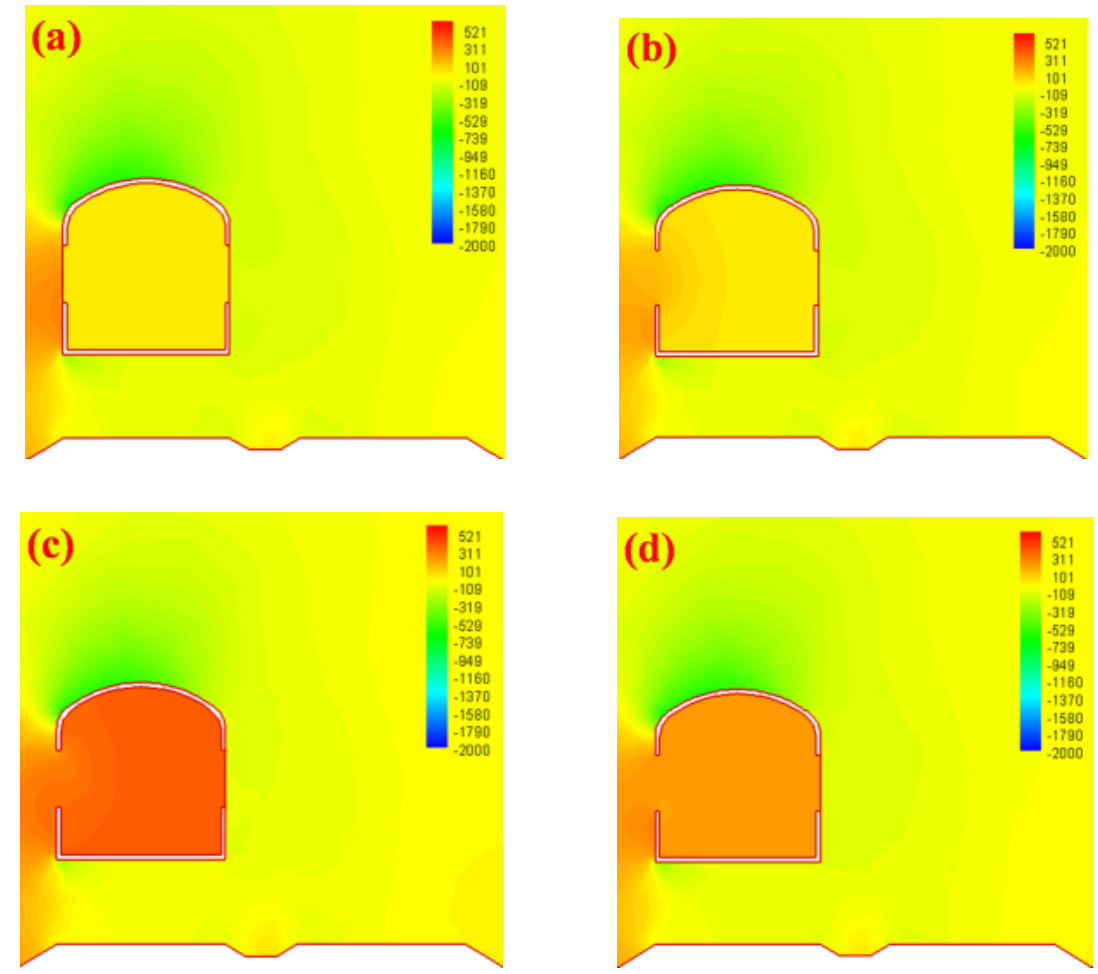

Fig. 8. Pressure distribution at the coach cross-sectional surface: (a) $t=0.5 s$, (b) $t=1.01 s$, (c) $t=1.08$ s, (d) $\mathrm{t}=\mathbf{4} \mathrm{s}$.

the train, the pressure increases as the flow speed decreases owing to flow retention, as shown in Fig. 8 (a); the kinetic energy transforms into pressure energy. When $\mathrm{t}=1.01 \mathrm{~s}$, i.e., $0.01 \mathrm{~s}$ after the window breakage, the outer airflow penetrates the interior of the passenger car and hit the interior surface of the opposite side. The air inside the passenger car is suddenly compressed, thus resulting in a gradual pressure increase along the direction from the broken window to the interior of the passenger car, as shown in Fig. 8(b). When $\mathrm{t}=1.08 \mathrm{~s}$, the streamlines are reflected back to the broken window after they have 
reached the other side of the interior of the train, as shown in Fig. 7(c).In addition, the suddenly rushed airflow causes the pressure inside the passenger car to far exceed the pressure outside the window, as shown in Fig. 8(c), thus forcing the airflow to exit the window with a high speed and to flow upward across the roof of the train. In this manner, the evaluation of the airflow causes a pressure fluctuation inside the second passenger car with the broken windows. When $\mathrm{t}=4 \mathrm{~s}$, the pressure caused by the sudden highspeed airflow that had entered from the broken window encountered the reflected pressure; this resulted in a balance between the pressures inside and outside the train. The pressure encounter is illustrated by means of streamlines, shown in Fig. 7(d). The pressure balance can be seen in Fig. 8(d) as well. As shown in Fig. 8(d), the different pressure levels that appear in Figs. 8(b) and 8(c) have been eliminated at $\mathrm{t}=4 \mathrm{~s}$. Figure 9 shows the pressure change in the monitoring point that is located at the position where the highest instantaneous pressure amplitudes occur. The changes in the pressure values over the time verified the entire process of the variation in the flow structure in the train model. As can be seen from the pressure change curve, the pressure inside the coach rapidly increases from $0 \mathrm{~Pa}$ to the maximum value within a very short time after the breaking of the windows, and it then reaches a steady value after a period of fluctuations.

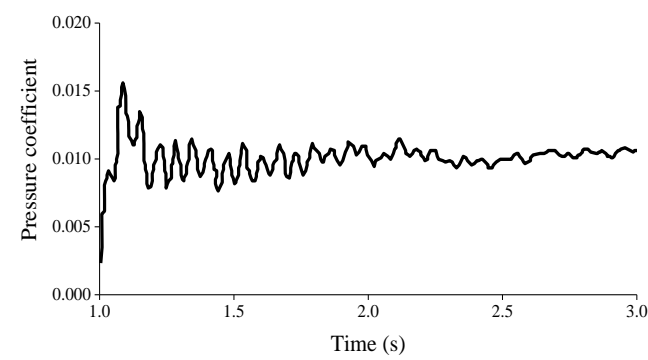

Fig. 9. Pressure changes over time for the monitoring of the point with the highest instantaneous pressure amplitudes.

It can be concluded that the breaking of the window glass can result in a sudden pressure change inside the passenger car, thus causing a rather complex and rapid variation in the flow structures. The alternating inflow and outflow had a severe negative impact on the passenger comfort. More specifically, the high speed airflow that entered into the passenger car could result in a sudden change in the aerodynamic forces of the train as well, thus potentially compromising the train safety. Owing to the strongwind environment, the drag force, the lift force, the side force, and the overturning moment were all affected; however, the lift force, the side force, and the overturning moment of the train were the main factors for the overturning of the train that had been induced by the strong crosswinds. Nevertheless, the simulation results shown in Fig. 8 indicated that the top and bottom pressure distributions inside the coach were similar both before and after the breaking of the windows, which means that they counterbalance one another; outside the train, the change in the pressure distribution on the roof and at the bottom was not obvious. Therefore, the window breakage did not strongly affect the lift force. Thus, this work was focused on the changes in the side force and the overturning moment of the train before and after the windows breakage. The changes in the side force and the overturning moment over time are shown in Figs. 10 and 11, respectively.

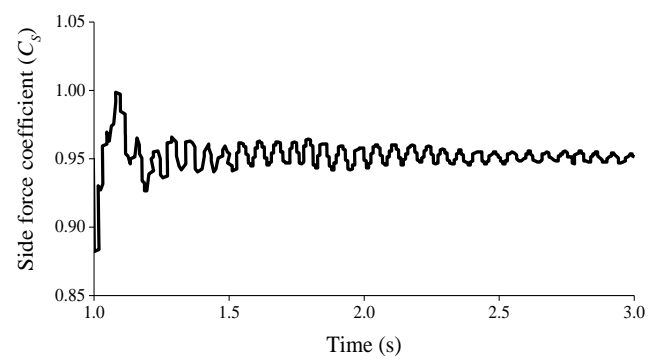

Fig. 10. Changes in the side force over time.

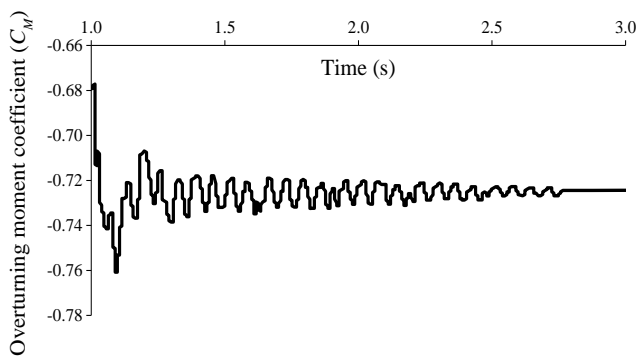

Fig. 11. Changes in the overturning moment over time.

Figure 10 indicates that the side force was stable before the breaking of the window; however, its value suddenly decreases by $7.2 \%$ within a very short time after the window breakage $(\mathrm{t}=1.01 \mathrm{~s})$. Then, the side force rapidly increases to its maximum value at $\mathrm{t}=1.08 \mathrm{~s}$, which is $4.9 \%$ greater than that before the glass breakage occurred. Finally, it decreases again and fluctuates until it reaches an approximately steady value when $t=4 \mathrm{~s}$. At this moment, the side force also returned to its initial value before the break of the window glass. This behavior can be explained by means of the variation in the airflow outside and inside the studied passenger car. As shown in Fig. 8 (b), the pressure around the breakage region is relatively higher than that inside train. In addition, the figure illustrates different pressure levelsdenoting different pressure values-which indicate that the broken windows caused the airflow to enter the car. However, the airflow entering from the broken window has only travelled a short distance inside the car; thus, the pressure on other parts of the inside of the car remained stable when $t=1.01 \mathrm{~s}$, which was $0.01 \mathrm{~s}$ after the breakage of window glass had occurred. As shown in Fig. 8(a), when the window is still intact, there is a high positive pressure on the windward train surface around the window and a negative pressure around the leeward side; therefore, the side force that is exerted along the windblown direction is high. However, the breakage 
of the window, which was induced by the rush of the airflow into the inner car, results in a sudden decrease in the positive pressure around the window when $t=1.01 \mathrm{~s}$, as shown in Fig. 8(b). In addition, the change in the flow structure around the train does not affect the negative pressure at the leeward side when $\mathrm{t}=1.01 \mathrm{~s}$; thus, the side force at the windblown direction presents a sudden decrease when the window on the windward side has broken. This result can be verified via the pressure changes shown in Fig. 9. As time progressed, more airflows rushed into the train and acted on the side of the train that is opposite to the window, thus resulting in a high positive pressure, as shown in Fig. 8(c). Thus, a new side force was generated inside the passenger car and the side force increased as the pressure inside the car rapidly increased. When $\mathrm{t}=1.08 \mathrm{~s}$, the pressure on this side of the inside of the train reached its maximum value, which was far greater than that of the positive pressure around the windward train window outside the train; this means that the side force reached its peak value as well. The aforementioned explains the sharp increase in the side force shown in Fig. 10. Then, the pressure inside the car fluctuated over time, causing similar fluctuations in the side force; however, the fluctuation of pressure inside the train decreased over time. When $\mathrm{t}=4 \mathrm{~s}$, the pressure inside the car was approximately equal to the pressure outside the car; the side force had returned to its initial value prior to the window breakage.

The overturning moment can be affected by both the lift and the side forces, but the overturning moment was mainly determined by means of the side force (Cheli et al. 2010; Wang et al. 2014; Zhang et al. 2015). This is the reason why the side force and overturning moment-shown in Figs. 10 and 11, respectively-present a similar change trend. As shown in Fig. 11, when the window breaks, the absolute value of the overturning moment decreases by approximately $7 \%$ compared with the value of the overturning moment prior to the window breakage. Then, the absolute value of the overturning moment increases up to its maximum value within a short time, and the increase was approximately $5 \%$. Finally, after a temporary fluctuation, it returns to its initial value, which corresponds to the value of the overturning moment before the glass breakage.

The overturning moment is the main factor that affects the train overturning safety. The breakage of the window glass caused the increase in the absolute value of the overturning moment by approximately $5 \%$ in a very short time, thus resulting in potential safety risks, particularly when the value of the wind speed was close to the value of the critical wind speed or when it exceeded the critical value. In addition, the window breakage caused the aerodynamic performance of the train to deteriorate under exposure to crosswinds; hence, the influence of the broken windows on the aerodynamic performance of the train should be considered while designing the operation management standards. Moreover, the overturning moment reached its maximum value within $0.08 \mathrm{~s}$. Thus, taking measures such as actively breaking the leeward windows within this very short time is impossible. Therefore, we suggest either improving the glass strength or installing a windbreak to prevent the train windows from breaking when the train is designed for operation along the railway lines that are located at the strong-wind area-where the sands and gravels can be blown away by the wind-in order to eliminate potential safety risks.

\subsection{The Effect of Wind Angles on the Aerodynamic Forces}

The wind angle is an important factor that affects the train aerodynamic performances .A train may encounter various wind angles when crossing strongwind areas; therefore, it is necessary to study the effects of the wind angles on the aerodynamic forces of the train when the window glass has been broken. In this simulation configuration, the 6th and 7th windows were assumed to be broken and the wind speed with an angle that ranged from $0^{\circ}$ to $90^{\circ}$ was $30 \mathrm{~m} / \mathrm{s}$. In addition, the side force and the overturning moment coefficients that were obtained with and without broken windows were compared. The changes in the side force and the overturning moment coefficients of the second passenger car for various wind angles are shown in Figs. 12 and 13.

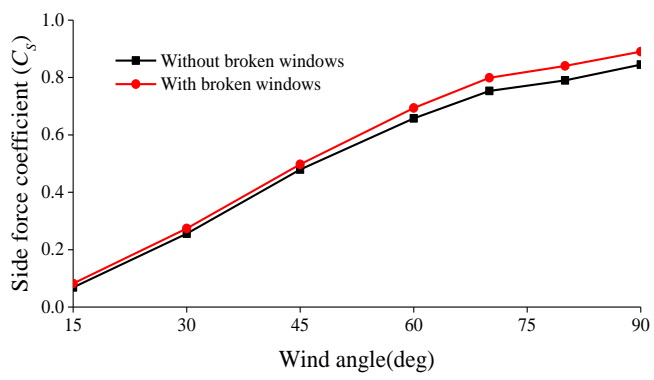

Fig. 12. Comparison of the side force coefficient.

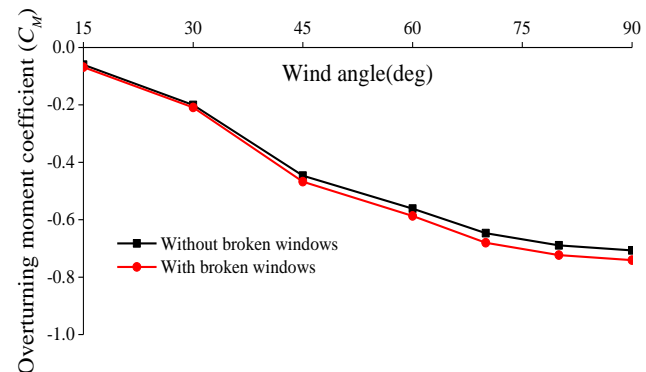

Fig. 13. Comparison of the overturning moment coefficient.

As shown in Figs. 12 and 13, the absolute values of the side force and of the overturning moment coefficients rapidly increase with the increase in the wind angle and reached their maximum values at a wind angle of $90^{\circ}$. The change trend of the second passenger car with broken windows was similar to that without broken windows. According to the comparisons in Figs. 12 and 13, the absolute values of the side force and the overturning moment 
coefficients of the second passenger car with broken windows are greater than those without broken windows. The differences between the side force values of the second passenger car with and without broken windows are not obvious when the wind angles are less than $30^{\circ}$. However, this difference is enhanced with the increase in the wind angle. As can be seen from Figs. 12 and 13, the maximum difference occurs when the wind angle is $90^{\circ}$. Thus, a train with broken windows that crosses strong-wind areas runs a higher risk of overturning.

\subsection{The Effect of the Number of Broken Windows on the Aerodynamic Forces}

In the previous section, the effect of the wind angles on the aerodynamic forces was studied when the 6th and 7th windows broke. However, in an actual situation, as shown in Fig. 2, multiple windows may break. Therefore, in this section, the same method will be used to determine the effect of the number of broken windows on the aerodynamic forces. The most dangerous wind angle for a train with broken windows that travels along the railway line is $90^{\circ}$; thus, this wind angle was used for the numerical simulations. First, the 6th and 7th windows at the center of the train were assumed to be broken; then, the adjacent two windows (5th and 8th) were assumed to be broken. According to this order, two additional windows were assumed to break in each new simulation until all 12 windows that were located at the windward side had been broken. The side forces and the overturning moment of the train were calculated when a different number of windows would break; these aerodynamic forces were compared with those obtained when no windows had been broken. As previously described, the absolute value of the side force and the overturning moment significantly increased when the windows broke. The increase rates of the maximum absolute value of the side force and of the overturning moment can be clearly seen in Fig. 14.

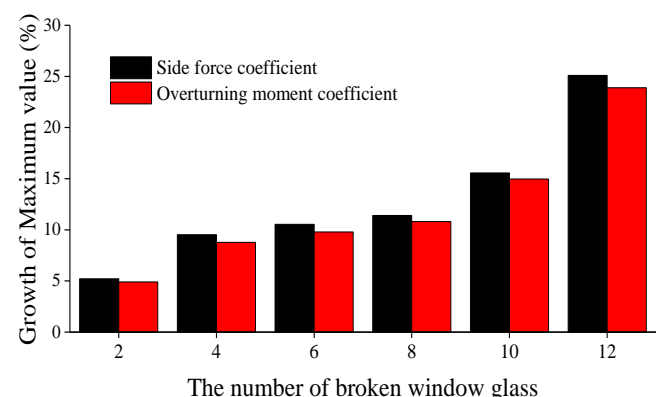

Fig. 14. The increase rates of the aerodynamic force compared with the configuration when no windows were broken.

As can be seen from Fig. 14, the maximum absolute values increased significantly as the number of the broken windows on windward side increased. When all 12 windows located at the windward side had broken, the increase rate of the maximum absolute value of the aerodynamic forces reached approximately $25 \%$ compared with that obtained when the windows had not broken. However, the increase rates of the maximum absolute value of the side force and of the overturning moment did not increase linearly with the increase in the number of broken windows. When the number of broken windows increased from two to four, the increase rates of the aerodynamic forces significantly increased compared with the forces obtained from other simulation configurations. Compared with the aerodynamic forces that were exerted when two windows had been broken, the aerodynamic forces increased by approximately $90 \%$ when four windows had been broken. As shown in Fig. 14, although the aerodynamic forces of the train increase when the number of broken windows increases from four to eight, the increase in the aerodynamic forces was not particularly sharp; compared with the aerodynamic forces that were exerted when four windows had been broken, the aerodynamic forces increased by approximately $21 \%$ when eight windows had been broken. However, the increase in the aerodynamic forces became significant again when the number of broken windows increased from eight to twelve; the aerodynamic forces increased by approximately $45 \%$ when the number of broken windows was 10 compared with the aerodynamic forces when the number of broken windows was 8 . Moreover, an increase of approximately $56 \%$ may be observed when number of broken windows was 12 compared with when number of broken windows was 10 . In addition, the overturning moment had the same increase trend as that of the side force. Because the overturning moment is mainly composed of the lift force and the side force, the increase in the lift force was significantly smaller than that of the side force. As previously described, the influence of the broken windows on the lift force was minor; thus, the increase rate of the overturning moment and that of the side force were close to one another. The overturning moment is the main factor that is used for the assessment of the overturning safety. The increase rate of the maximum absolute values of the side force and the overturning moment increased by approximately $5-25 \%$ when the number of broken windows that were located at the windward side increased from 2 to 12 compared with the values obtained from the configuration without broken windows.

\section{Conclusion}

Numerical simulations were executed to study the influence of the broken windows on the aerodynamic performance of the train. Moreover, the airflow streamlines and the pressure distributions that were affected by the broken windows were analyzed. The following conclusions were obtained.

(1) For the second passenger car, the breakage of the middle two windows (namely, the 6th and 7th windows out of a total of 12), which were located at the windward side, instantaneously caused the pressure inside the coach to increase. Moreover, they caused an inflow and outflow of air through 
the broken windows when the train would cross the strong-wind area, which severely affected the passenger comfort. The influence of the two broken windows on the train side force and the overturning moment was greater than on the lift force. The absolute values of the train side force and the overturning moment first decreased and then rapidly increased within a very short period. The maximum increase in the amplitude of the side force and in the overturning momentum was approximately $5 \%$, whereas the influence on the lift force was minor. In addition, the absolute value of the side force and of the overturning moment increased with the increase in the wind angles (from $0^{\circ}$ to $90^{\circ}$ ), and reached their maximum when the wind angle was $90^{\circ}$.

(2) The absolute value of the side force and of the overturning moment increased significantly with the increase in the number of broken windows on windward side. According to the simulation configurations that were investigated in this study, the increase in the absolute value of the side force and of the overturning moment was greater when the number of broken windows increased from two to four and from eight to twelve than it was when the number of broken windows increased from four to eight. The maximum absolute value of the side force and of the overturning moment increased by approximately $5-25 \%$ when the number of broken windows that were located at the windward side increased from two to twelve compared with the corresponding maximum absolute values obtained from the configuration without broken windows.

\section{ACKNOWLEDGEMENTS}

The authors would like to acknowledge the financial support from the National Key R\&D Program of China (Grant number 2016YFB1200602-11, 2016YFB1200602-12).

\section{REFERENCES}

Baker, C. J. (1986). Train aerodynamic forces and moments from moving model experiments. Journal of Wind Engineering and Industrial Aerodynamics 24, 227-251.

Baker, C. J. (2010). The simulation of unsteady aerodynamic cross wind forces on trains. Journal of Wind Engineering and Industrial Aerodynamics 98, 88-99.

Baker, C. J. and S. Reynolds (1992). Wind-induced accidents of road vehicles. Accident; analysis and prevention $24,559-575$.

Bettle, J., A. G. L. Holloway and J. E. S. Venart (2003). A computational study of the aerodynamic forces acting on a tractor-trailer vehicle on a bridge in cross-wind. Journal of Wind Engineering and Industrial Aerodynamics 91, 573-592.
Bocciolone, M., F. Cheli, R. Corradi, S. Muggiasca and G. Tomasini (2008). Crosswind action on rail vehicles: Wind tunnel experimental analyses. Journal of Wind Engineering and Industrial Aerodynamics 96, 584-610.

CEN European Standard (2008). CSN EN 14067-6 Railway applications - Aerodynamics - Part 6: Requirements and test procedures for cross wind assessment. Eur. Norm.

CEN European Standard (2009). EN 14067-4 Railway Applications-Aerodynamics-Part 4: Requirements and Test Procedures for Aerodynamics on Open Track. CEN.

CEN European Standard (2010). CEN EN 14067-6 Railway Applications-Aerodynamics-Part 6: Requirements and Test Procedures for Cross Wind Assessment. CEN.

Cheli, F., F. Ripamonti, D. Rocchi and G. Tomasini (2010). Aerodynamic behaviour investigation of the new EMUV250 train to cross wind. Journal of Wind Engineering and Industrial Aerodynamics 98, 189-201.

Fluent Inc. FLUENT User's Guide (2006).

Gao, G. J., J. Zhang and X. H. Xiong (2014). Location of anemometer along LanzhouXinjiang railway. Journal of Central South University 21, 3698-3704.

García, J., J. Muñoz-Paniagua and A. Crespo (2017). Numerical study of the aerodynamics of a full scale train under turbulent wind conditions, including surface roughness effects. Journal of Fluids and Structures 74, 1-18.

Ge, S. C. and F. Q. Jiang (2009). Analyses of the Causes for Wind Disaster in Strong Wind Area along Lanzhou-Xinjiang Railway and the Effect of Windbreak. Journal of Railway Engineering Society 5, 1-4. [in Chinese].

Hemida, H. and C. J. Baker (2010). Large-eddy simulation of the flow around a freight wagon subjected to a crosswind. Computers and Fluids 39, 1944-1956.

Huang, S., H. Hemida and M. Yang (2016). Numerical calculation of the slipstream generated by a $\mathrm{CRH} 2$ high-speed train. Proceedings of the Institution of Mechanical Engineers Part F: Journal of Rail and Rapid Transit 230, 103-116.

Hucho, W. and G. Sovran (1993). Aerodynamics of Road Vehicles. Annual Review of Fluid Mechanics 25, 485-537.

Imai, T., T. Fujii, K. Tanemoto, T. Shimamura, T. Maeda, H. Ishida and Y. Hibino (2002). New train regulation method based on wind direction and velocity of natural wind against strong winds. Journal of Wind Engineering and Industrial Aerodynamics. Fifth Asia-Pacific Conference on Wind Engineering 90, 16011610. 
Ji, P., F. Wu, B. Qian, L. Yan (2019). Aerodynamic Shape Design of Pantograph Network Monitoring Device on High-Speed Trains. Journal of Applied Fluid Mechanics 12(5), 1383-1394.

Krajnović, S (2008). Numerical simulation of the flow around an ICE2 train under the influence of a wind gust. Proceedings of the Institution Conference on Railway Engineering 2008 (IET ICRE2008), Challenges for Railway Transportation in Information Age, Hong Kong, China, 25-28.

Li, Y. and H. Tian (2012). Lateral aerodynamic performance and speed limits of double-deck container vehicles with different structures. Journal of Central South University 19, 20612066.

Li, Y., H. Tian and M. Yang (2011). Aerodynamic drag analysis of double-deck container vehicles with different structures. Journal of Central South University 18, 1311-1315.

Niu, J., D. Zhou and X. Liang (2017a). Numerical simulation of the effects of obstacle deflectors on the aerodynamic performance of stationary high-speed trains at two yaw angles. Proceedings of the Institution of Mechanical Engineers Part F: Journal of Rail and Rapid Transit 232, 913-927.

Niu, J., D. Zhou, and X. Liang (2017b). Numerical investigation of the aerodynamic characteristics of high-speed trains of different lengths under crosswind with or without windbreaks. Engineering and Applications Computational Fluid Mechanics 12, 195-215.

Paz, C., E. Suárez, C. Gil and M. Concheiro (2015). Numerical study of the impact of windblown sand particles on a high-speed train. Journal of Wind Engineering and Industrial Aerodynamics 145, 87-93.

Peters, J. L (2004). How to reduce the cross wind sensitivity of trains. The Aerodynamics of Heavy Vehicles: Trucks, Buses, and Trains, Springer 19, 453-467.

Sanquer, S., C. Barré, M. D. de Virel and L.-M. Cléon (2004). Effect of cross winds on highspeed trains: development of a new experimental methodology. Journal of Wind Engineering and Industrial Aerodynamics, A selection of papers derived from those presented at the 11th International Conference on Wind Engineering 92, 535-545.

Shirai, S and T. Ueda (2003). Aerodynamic simulation by CFD on flat box girder of superlong-span suspension bridge. Journal of Wind Engineering and Industrial Aerodynamics, Fifth Asia-Pacific Conference on Wind Engineering 91, 279-290.

Suzuki, M., K. Tanemoto, and T. Maeda (2003). Aerodynamic characteristics of train/vehicles under cross winds. Journal of Wind Engineering and Industrial Aerodynamics, Fifth Asia-Pacific Conference on Wind Engineering 91, 209-218.

Wang, Y., Y. Xin, Z. Gu, S. Wang, Y. Deng and X. Yang (2014). Numerical and Experimental Investigations on the Aerodynamic Characteristic of Three Typical Passenger Vehicles. Journal of Applied Fluid Mechanics 7(4), 659-671.

Xiong, X., X. Liang, G. Gao. T. Liu (2006). Train aerodynamic characteristics in strong crosswind on Lanzhou-Xinjiang railway line. Journal of Central South University 37(6), 1183-1188.

Xu, G., X. Liang, S. Yao, D. Chen and Z. Li (2017). Multi-Objective Aerodynamic Optimization of the Streamlined Shape of High-Speed Trains Based on the Kriging Model. PLoS One 12(1), $1-14$

Xu, L. Z., X. F. Liang, H. T. Liu and Z. G. Wang (2014). Experiment test of wind-sand flow destruction to train tempered glass. Journal of Central South University 45, 2489-2495.

Zhang, J., G. Gao, T. Liu and Z. Li (2017). Shape Optimization of a Kind of Earth Embankment Type Windbreak Wall along the LanzhouXinjiang Railway. Journal of Applied Fluid Mechanics 10(4), 1189-1200.

Zhang, J., G. J. Gao, T. H. Liu and Z. W. Li (2015). Crosswind stability of high-speed trains in special cuts. Journal of Central South University 22(7), 2849-2856.

Zhang, J., J. Li, H. Tian, G. Gao and J. Sheridan (2016). Impact of ground and wheel boundary conditions on numerical simulation of the highspeed train aerodynamic performance. Journal of Fluids and Structure 61, 249-261. 